\title{
An overview of systematic reviews of the use of systemic antimicrobials for the treatment of periodontitis
}



\author{
C. M. Faggion Jr, ${ }^{* 1}$ M. P. Cullinan, ${ }^{2}$ M. Atieh ${ }^{3}$ and J. Wasiak ${ }^{4}$
}

\begin{abstract}
Background Systemic antimicrobials have been used as an adjunctive therapy for the treatment of periodontitis. Nevertheless, it is unclear whether the use of antimicrobials may improve tooth survival in patients with periodontitis. The main objective of this overview of systematic reviews (SRs) with meta-analyses was to assess the evidence supporting systemic antimicrobials for improving tooth survival in patients suffering from periodontitis. Information on adverse events was also extracted from SRs. Methods PubMed and EMBASE databases were searched independently (up to 1st August 2013) to identify SRs with meta-analyses on the use of systemic antimicrobials as an adjunctive treatment to scaling and root planing (SRP) in the treatment of periodontitis. Tooth survival and adverse events were assessed. Clinical effect was also assessed based on endpoints including clinical attachment level and probing depth. The methodological quality of the SRs was assessed by two authors using two checklists (AMSTAR and 00A0). Results No data on tooth survival after treatment with SRP and antimicrobials were found. Nine SRs were included in this overview. Three SRs showed statistically significant outcome improvement with the use of antimicrobials, although the clinical relevance may be questionable. One SR showed better results based on surrogate endpoints; however, short-term adverse events were more pronounced with the use of antimicrobials. The reporting of long-term data on clinical effects, adverse events and bacterial resistance is scarce. The SRs were of heterogeneous quality. Conclusions Evidence of the efficacy of systemic antimicrobials on improving tooth survival is lacking. Further research focused on tooth survival and adverse events should be performed to provide more robust evidence of the benefits of using systemic antimicrobials for treating periodontitis.
\end{abstract}

\section{INTRODUCTION}

Periodontal diseases affect the soft and hard tissues surrounding the teeth, and can contribute to tooth loss. Although several therapeutic approaches have been suggested, mechanical debridement is the standard approach for treating periodontitis. ${ }^{1-6}$ To enhance the effectiveness of therapy, systemic antimicrobials have been used with mechanical root scaling. Many reports suggest that clinical endpoints such as clinical attachment level (CAL) and pocket depth (PD) are improved with the use of

\footnotetext{
Department of Periodontology, Faculty of Dentistry, University of Münster, Münster, Germany, Waldeyerstraße 30, 48149 Münster, Germany; ${ }^{2}$ Faculty of Dentistry, University of Otago, Dunedin, New Zealand; ${ }^{3}$ Oral Implantology Research Group, Sir John Walsh Research Institute, Department of Oral Sciences, Faculty of Dentistry, University of Otago, Dunedin, New Zealand; ${ }^{4}$ Melbourne Dental School, University of Melbourne, 720 Swanston Street, Victoria, Australia ${ }^{*}$ Correspondence to: Clovis Mariano Faggion Jr Tel: +49 (0)251 8347061; Fax: +49 (0)251 8347134. Email: clovisfaggion@yahoo.com
}

\section{Refereed Paper}

Accepted 8 August 2014

DOI: 10.1038/sj.bdj.2014.909

${ }^{\circledR}$ British Dental Journal 2014; 217: 443-451 systemic antibiotics. ${ }^{7-10}$ However, the risk of adverse events, such as bacterial resistance, also needs to be considered, ${ }^{11,12}$ and more data on whether systemic antimicrobial use improves tooth survival are needed. Improvements in surrogate endpoints such as CAL and PD do not necessarily indicate future tooth survival.

An overview of systematic reviews (SRs) allows the synthesis of data from several reviews in a single document. This may benefit practitioners, researchers and policy makers looking for a comprehensive view of the evidence about the topic of interest. ${ }^{13}$ Therefore, the main objective of this paper was to critically assess whether the adjunctive use of systemic antimicrobials for the treatment of periodontitis may lead to improved tooth survival. We analysed evidence from SRs with metaanalyses (MAs) which are considered the pinnacle of the hierarchy of evidence to support decision-making. Moreover, we also critically assessed and interpreted the results of SRs based on the surrogate endpoints CAL and PD and potential adverse events.

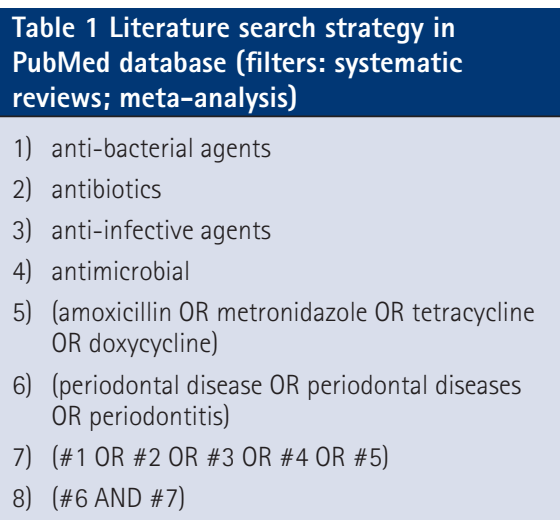

\section{MATERIALS AND METHODS}

Research question, data sources and search strategies

In order to guide this critical appraisal, the following research question was developed: 'Does the use of systemic antibiotics as an adjuvant to mechanical therapy improve tooth survival in patients suffering from periodontitis?' A structured literature search was performed in PubMed and EMBASE electronic databases using the keywords: antibiotics and periodontitis. The last search was performed 


\begin{tabular}{|c|c|c|c|c|c|c|}
\hline Studies & $\begin{array}{l}\text { Study designs } \\
\text { included }\end{array}$ & $\begin{array}{l}\text { Disease } \\
\text { classification }\end{array}$ & Intervention & Comparison & Endpoints reported & $\begin{array}{l}\text { Is tooth } \\
\text { survival } \\
\text { reported? }\end{array}$ \\
\hline Hayes et al. $1992^{19}$ & RCTs and CCTs & Periodontitis & SRP + tetracycline, tetracycline & SRP, placebo & $\mathrm{PD}$ and $\mathrm{CAL}$ & No \\
\hline Elter et al. $1997^{20}$ & RCTs & Periodontitis & $\mathrm{SRP}+$ metronidazole & SRP & CAL and PD & No \\
\hline $\begin{array}{l}\text { Herrera et al. } \\
2002^{21}\end{array}$ & RCTs and CCTs & $\begin{array}{l}\text { Aggressive } \\
\text { and chronic } \\
\text { periodontitis }\end{array}$ & $\begin{array}{l}\text { SRP + tetracyclines (tetracycline CIH, } \\
\text { doxycycline, minocycline), MET and } \\
\text { ornidazole, penicillins (AMX, AMXI } \\
\text { clavulanate, penicillin), macrolides } \\
\text { (erythromycin, spiramycin, } \\
\text { azithromycin, oxithromycin), } \\
\text { clindamycin, ciprofloxacin, and } \\
\text { different combinations of these } \\
\text { drugs (AMX/MET, /spiramycin, etc.) }\end{array}$ & SRP & Mean change in CAL and PD & No \\
\hline $\begin{array}{l}\text { Haffajee et al. } \\
2003^{22}\end{array}$ & $\begin{array}{l}\text { RCTs, CCTs, } \\
\text { and cohorts }\end{array}$ & $\begin{array}{l}\text { Aggressive } \\
\text { and chronic } \\
\text { periodontitis }\end{array}$ & $\begin{array}{l}\text { Single systematically administered } \\
\text { antibiotic alone or combined with } \\
\text { SRP or surgery }\end{array}$ & $\begin{array}{l}\text { Placebo, SRP, } \\
\text { surgery }\end{array}$ & $\begin{array}{l}\text { CAL mean, } \% \text { of sites } \\
\text { exhibiting AL over a given } \\
\text { threshold, PD }\end{array}$ & No \\
\hline Bono et al. $2010^{23}$ & RCTs & & AMX+MET or AMX or MET & SRP & CAL and PD & No \\
\hline $\begin{array}{l}\text { Sgolastra et al. } \\
2012^{25}\end{array}$ & RCTs & $\begin{array}{l}\text { Chronic } \\
\text { periodontitis }\end{array}$ & $S R P+A M X+M E T$ & SRP & $\begin{array}{l}\text { Full-mouth CAL, full-mouth } \\
\text { PD, as well as CAL gain } \\
\text { and PD reduction stratified } \\
\text { according to baseline PD }\end{array}$ & No \\
\hline $\begin{array}{l}\text { Sgolastra et al. } \\
2012^{26}\end{array}$ & RCTs & $\begin{array}{l}\text { Aggressive } \\
\text { periodontitis }\end{array}$ & $S R P+A M X+M E T$ & SRP & $\begin{array}{l}\text { Full-mouth CAL gain, } \\
\text { full-mouth PD reduction, } \\
\text { as well as CAL gain and } \\
\text { PD reduction stratified } \\
\text { according to baseline PD }\end{array}$ & No \\
\hline $\begin{array}{l}\text { Sgolastra et al. } \\
2013^{27}\end{array}$ & RCTs & $\begin{array}{l}\text { Chronic } \\
\text { periodontitis }\end{array}$ & $\mathrm{SRP}+\mathrm{MET}$ & SRP & CAL and PD & No \\
\hline $\begin{array}{l}\text { Zandbergen et al. } \\
2013^{24}\end{array}$ & $\begin{array}{l}\text { RCTs, CCTs, } \\
\text { prospective } \\
\text { clinical studies, } \\
\text { or case series }\end{array}$ & $\begin{array}{l}\text { Aggressive } \\
\text { and chronic } \\
\text { periodontitis }\end{array}$ & $A M X+M E T+S R P$ & SRP & CAL and PD & No \\
\hline
\end{tabular}

on 1st August 2013. The predefined search strategy was designed for maximal retrieval using MeSH (medical subject headings) and free text searching (Table 1). 'In the process of choosing key-words for the search, balance between more generic synonyms for antimicrobials and more specific terms designating the most used antimicrobials for treating periodontitis (that is metronidazole and amoxicillin) was sought. The thesaurus of each database was used to adapt the search terms. The timeframe was chosen to include older references and monitor the progression of the literature over time. In addition, reference lists of select journal articles, three periodontal journals (Journal of Clinical Periodontology, Journal of Periodontology and Journal of Periodontal Research), and existing reviews were manually searched for additional references. The authors conducted independent literature searches, and disagreements over the initial search outputs were resolved by discussion. All searches were limited to articles published in English.

\section{Study selection and criteria}

All SRs with meta-analyses that assessed the effects of systemic antimicrobials use with non-surgical mechanical treatment of periodontitis were considered for inclusion in this review. SRs with meta-analyses that examined host modulatory therapies including sub antimicrobial-dose doxycycline, local anti-infective agents, both local and systemic antimicrobials, and systematic reviews including animal studies were excluded. Two authors scanned the references retrieved by the initial search to exclude irrelevant studies. Full-text articles were retrieved and reviewed independently by two authors to determine inclusion after consensus was reached.

\section{Data extraction}

The authors independently extracted data using standardised forms. The data included: 1) results based on true endpoints such as tooth survival, ${ }^{14}$ 2) surrogate endpoints including CAL and PD measurements, and 3) adverse events. Adverse events were defined as injuries related to medical management, not complications of disease. Medical management included all aspects of care including diagnosis, treatment, failure to diagnose or treat, and the systems and equipment used to deliver care. ${ }^{15}$ The recommendations of the SRs regarding the use of antimicrobials as adjuvant treatment for periodontitis were also extracted. The assessments of the two reviewers were compared, the final dataset determined after discussion and a consensus was reached.

\section{Quality assessment}

The methodological quality of the SRs included was determined using the assessment of multiple systematic reviews (AMSTAR) checklist, which is a validated checklist comprising 11 items addressing specific, important aspects of an SR. ${ }^{16,17}$ This tool was used to assess search strategies, inclusion and exclusion criteria, and the methodological qualities of trials included in the review. A second checklist, the overview quality assessment questionnaire (OQAQ), was used to assess the methodological quality of reviews included. ${ }^{18}$ OQAQ consists of a scale that is divided into nine areas related to the search methodology, selection criteria, assessment of the included studies, methods used to combine the findings, and overall 


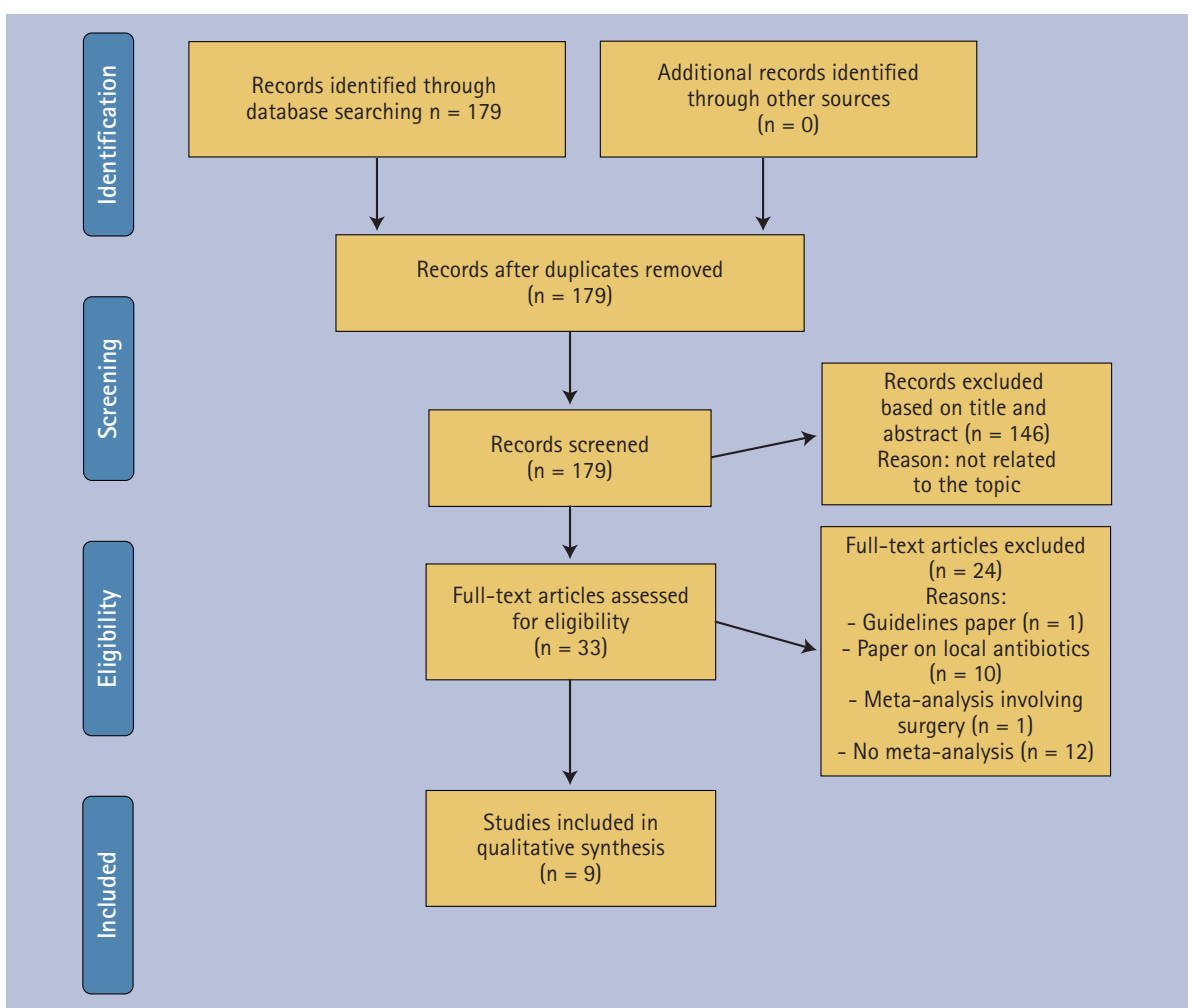

Fig. 1 PRISMA flowchart describing the literature search

scientific quality of the conclusions. We did not include the tenth question from OQAQ, because it is related to a final quality score for the review assessed. This measure was taken due to the difficulty of weighing domains assessed to achieve a final quality score, as well as to keep homogeneity in the assessment with AMSTAR (which does not include a final score). For the sake of simplicity, each of the checklist items was scored 'Yes' or 'No'. 'Yes' indicated that the assessed criteria were explicitly met in the SR, and 'No' indicated that the assessed criteria were not met or that they were not described by the authors. The number of items assigned 'Yes' indicated higher methodological quality of the reviews. Two authors performed the methodological quality assessments of SRs independently, and disagreements were resolved by discussion until a consensus was achieved.

\section{Training of reviewers}

Before the SRs were analysed with the checklists, reviewers performed practice assessments to streamline the process. Three rounds with three SRs in each round were assessed independently and in duplicate. The results of each assessment were compared and disagreements were discussed to improve homogeneity.

\section{RESULTS}

The initial search retrieved 179 articles. After screening titles and abstracts, 146 articles were excluded. Full-text reviews of the remaining 33 articles resulted in the exclusion of 24 articles, which left nine SRs for inclusion in the study (Table 2). ${ }^{19-}$

${ }^{27}$ Figure 1 illustrates the literature search results in detail.

\section{Results}

\section{Tooth survival}

No tooth loss was reported in the nine SRs assessed (Table 2).

\section{CAL and PD (all periodontal pockets)}

The use of systemic antimicrobials increased mean PD reductions by $0.18 \mathrm{~mm}^{27}$ to $1.41 \mathrm{~mm}^{24}$ on average, in comparison to SRP alone. The number of studies included in the SRS with meta-analyses that assessed changes in PD varied from $3^{25}$ to $19^{24}$, and the followup time ranged from 1 to 24 months (Table 3). In the antimicrobials group, CAL improvements ranged from $0.045 \mathrm{~mm}^{22}$ to $0.94 \mathrm{~mm}^{24}$ on average. The number of studies included in the SRs with meta-analyses assessing changes in CAL varied from $4^{25}$ to $27 .{ }^{22}$

\section{CAL and PD (deep periodontal pockets)}

In cases of deep periodontal pockets, PD $>6 \mathrm{~mm}$ at baseline, on average CAL measurements improved with the use of antimicrobials from $0.262 \mathrm{~mm}$ (with spyramicin) to $0.551 \mathrm{~mm}$ (with metronidazole) (Table 4). ${ }^{21}$ In cases of PD $>6 \mathrm{~mm}$ at baseline, the use of amoxicillin and metronidazole and SRP produced an average improvement on CAL of $1.66 \mathrm{~mm}$ in comparison to SRP alone. ${ }^{24}$ In cases of $\mathrm{PD}>7 \mathrm{~mm}$ at baseline, CAL average values varied from $0.193 \mathrm{~mm}^{20}$ to $2.66 \mathrm{~mm} .^{24}$ The number of studies included in the SRs with meta-analyses assessing changes in CAL varied from two ${ }^{21}$ to eight. ${ }^{24}$

In cases of PD $>5 \mathrm{~mm}$ at baseline, tetracycline and SRP treatment reduced $\mathrm{PD}$ by $0.43 \mathrm{~mm}$ on average compared to SRP treatment alone. ${ }^{19}$ In cases of PPD $>6 \mathrm{~mm}$ at baseline, spiramycin reduced PD by $0.407 \mathrm{~mm}$ on average more than SRP treatment. ${ }^{21}$ In cases of PD $>6 \mathrm{~mm}$, amoxicillin, metronidazole and SRP combined treatment only reduced PD by $2.59 \mathrm{~mm}$ on average more than SRP. ${ }^{24}$ In cases of PD $>7 \mathrm{~mm}$ at baseline, average PD reductions varied from $0.7 \mathrm{~mm}^{20}$ to $3.72 \mathrm{~mm}$ compared to SRP treatment alone. ${ }^{24}$ The number of studies included in the SRs assessing changes in PD varied from two to eight (Table 4).

\section{Adverse events}

The prevalence of adverse events in patients treated with systemic antimicrobials varied greatly. Most adverse events reported were gastrointestinal. The complaints included nausea, vomiting, headache and metallic taste (Table 5). One SR reported a temporary increase in bacterial resistance. ${ }^{21}$

\section{Methodological quality of SRs}

With the AMSTAR checklist, SRs were scored from 1 to 9 (median = 8). Some checklist criteria were met in almost all SRs. For example, the questions, 'were the characteristics of the included studies provided?' and 'was the scientific quality of the included studies assessed and documented?' were reported in eight of the nine SRs assessed. In contrast, two questions, "was the status of publication used as an inclusion criterion?' and 'was the conflict of interest included' were not reported in any SRs assessed. The full AMSTAR assessment is reported in Table S1 in the Appendix.

With the OQAQ checklist, SRs were scored from 5 to 9 (median $=8)$. Some checklist criteria were met in all SRs, for example "were the search methods used to find evidence (original research) on the primary question (s) stated?' and 'were the criteria used for deciding which studies to include in the overview reported?' In contrast, one criterion ('was bias in the selection of studies avoided?') was met in three of nine SRs.

\section{DISCUSSION}

This overview of SRs reveals the lack of robust evidence supporting the use of systemic antimicrobials as adjuvant therapy to SRP for the treatment of periodontitis. To date, all evidence of antimicrobial effectiveness is based on surrogate endpoints such as PD and CAL. In addition, adjunctive use of 


\begin{tabular}{|c|c|c|c|c|c|}
\hline \multirow[t]{2}{*}{ Studies } & $\begin{array}{l}\text { Results on } \\
\text { effectiveness (in mm) }\end{array}$ & & $\begin{array}{l}\text { Number } \\
\text { of studies } \\
\text { included in the } \\
\text { meta-analyses* }\end{array}$ & $\begin{array}{l}\text { Time of } \\
\text { follow-up }\end{array}$ & Authors' conclusions ${ }^{+}$ \\
\hline & Fixed-effect model & $\begin{array}{l}\text { Random-effect } \\
\text { model }\end{array}$ & & & \\
\hline $\begin{array}{l}\text { Hayes et al. } \\
1992^{19}\end{array}$ & $\begin{array}{l}\text { No data on PD average } \\
\text { measurements }\end{array}$ & & NP & 25 weeks & $\begin{array}{l}\text { 'We conclude that analysis of data from the published literature } \\
\text { does not demonstrate that the use of systemic tetracycline is } \\
\text { more beneficial than conventional treatment in the management } \\
\text { of adult periodontal disease. More information is needed in order } \\
\text { to perform an extensive meta-analysis of this subject' }\end{array}$ \\
\hline $\begin{array}{l}\text { Elter et al. } \\
1997^{20}\end{array}$ & $\begin{array}{l}\text { No data on PD average } \\
\text { measurements }\end{array}$ & & NP & $\begin{array}{l}4 \text { to } 6 \\
\text { weeks }\end{array}$ & $\begin{array}{l}\text { 'These results suggest that MET in conjunction with SRP may } \\
\text { offer a benefit over SRP alone in the treatment of adult peri- } \\
\text { odontitis patients in managing pockets of } 4 \mathrm{~mm} \text { or greater, } \\
\text { but the additional benefit was not evident if initial PD was less } \\
\text { than } 4 \mathrm{~mm} \text { or follow-up was beyond } 13 \text { weeks' }\end{array}$ \\
\hline $\begin{array}{l}\text { Herrera et al. } \\
2002^{21}\end{array}$ & $\begin{array}{l}\text { No data on PD average } \\
\text { measurements }\end{array}$ & & NP & 24 weeks & $\begin{array}{l}\text { 'Systemic antimicrobials in conjunction with SRP, can offer } \\
\text { an additional benefit over SRP alone in the treatment of peri- } \\
\text { odontitis, in terms of CAL and PD change, and reduced risk of } \\
\text { additional CAL loss. However, differences in study methodology } \\
\text { and lack of data precluded an adequate and complete pooling } \\
\text { of data for a more comprehensive analyses. It was difficult to } \\
\text { establish definitive conclusions, although patients with deep } \\
\text { pockets, progressive or 'active' disease, or specific microbiologi- } \\
\text { cal profile, can benefit more from this adjunctive therapy'. }\end{array}$ \\
\hline $\begin{array}{l}\text { Haffajee et al. } \\
2003^{22}\end{array}$ & $\begin{array}{l}\text { CAL }(0.045 \text {, range } 0.09 \\
\text { to } 1.10)\end{array}$ & & 27 for $C A L$ & $\begin{array}{l}12 \text { to } 96 \\
\text { weeks }\end{array}$ & $\begin{array}{l}\text { '1) The use of systematically administered adjunctive antibiot- } \\
\text { ics with and without SRP and /or surgery appeared to provide a } \\
\text { greater clinical improvement in CAL than therapies not employing } \\
\text { these agents. 2) The data supported similar effect sizes for the } \\
\text { majority of the antibiotics; therefore, the selection for an indi- } \\
\text { vidual patient has to be made based on other factors. 3) Due to } \\
\text { lack of sufficient sample size for many of the antibiotics tested, it } \\
\text { is difficult to provide guidance as to the more effective ones' }\end{array}$ \\
\hline $\begin{array}{l}\text { Bono et al. } \\
2010^{23}\end{array}$ & & $\begin{array}{l}\text { PD (-1.1355, } \\
\text { Cl: }-2.5896 \text { to } \\
0.3186) ; C A L \\
(-0.4548, \text { Cl: } \\
-1.3035 \text { to } 0.3940) \\
\text { (favoring test) }\end{array}$ & $\begin{array}{l}6 \text { for PD } \\
5 \text { for } \mathrm{CAL}\end{array}$ & $\begin{array}{l}4 \text { to } 48 \\
\text { weeks }\end{array}$ & $\begin{array}{l}\text { 'This meta-analysis showed absence of statistically significant } \\
\text { difference between the effects studied' }\end{array}$ \\
\hline $\begin{array}{l}\text { Sgolastra et al. } \\
2012^{25}\end{array}$ & & $\begin{array}{l}\text { CAL }(0.21, \mathrm{Cl}: 0.02 \\
\text { to } 0.4) ; \mathrm{PD}(0.43 \\
\mathrm{Cl}: 0.24 \text { to } 0.63)\end{array}$ & $\begin{array}{l}4 \text { for } C A L \\
3 \text { for } P D\end{array}$ & $\begin{array}{l}12 \text { to } 96 \\
\text { weeks }\end{array}$ & $\begin{array}{l}\text { 'The findings of this meta-analysis seem to support the } \\
\text { effectiveness of SRP + AMX/MET; however, future studies are } \\
\text { needed to confirm these results' }\end{array}$ \\
\hline $\begin{array}{l}\text { Sgolastra et al. } \\
2012^{26}\end{array}$ & & $\begin{array}{l}\operatorname{CAL}(0.42, \mathrm{Cl}: 0.23 \\
\text { to } 0.61) ; \mathrm{PD}(0.58 \\
\mathrm{Cl}: 0.39 \text { to } 0.77)\end{array}$ & $\begin{array}{l}6 \text { for } C A L \\
6 \text { for } P D\end{array}$ & $\begin{array}{l}8 \text { to } 24 \\
\text { weeks }\end{array}$ & $\begin{array}{l}\text { 'The findings of the meta-analysis seem to support the } \\
\text { effectiveness and the clinical safety of FMSRP + AMX/ MET; } \\
\text { however, future studies are needed to confirm these results' }\end{array}$ \\
\hline $\begin{array}{l}\text { Sgolastra et al. } \\
2013^{27}\end{array}$ & & $\begin{array}{l}\text { PD }(0.18, \mathrm{Cl}: 0.09 \\
\text { to } 0.28) ; \text { CAL }(0.10 \\
\text { Cl: } 0.08 \text { to } 0.12)\end{array}$ & $\begin{array}{l}9 \text { for PD } \\
9 \text { for } C A L\end{array}$ & $\begin{array}{l}12 \text { to } 48 \\
\text { weeks }\end{array}$ & $\begin{array}{l}\text { 'The meta-analysis results seem to support the effectiveness of } \\
\text { adjunctive MET with SRP compared to SRP alone. However, given } \\
\text { the low number of included studies and limitations of meta- } \\
\text { analysis, future studies are needed to confirm these results' }\end{array}$ \\
\hline $\begin{array}{l}\text { Zandbergen } \\
\text { et al. } 2013^{*, 24}\end{array}$ & $\begin{array}{l}\text { PD }(-1.41, \mathrm{Cl}:-1.46 \text { to } \\
-1.37) ; \mathrm{CAL}(+0.94, \mathrm{Cl}: \\
+0.90 \text { to }+0.98)\end{array}$ & & $\begin{array}{l}19 \text { for } \mathrm{PD} \\
19 \text { for CAL }\end{array}$ & $\begin{array}{l}8 \text { to } 96 \\
\text { weeks }\end{array}$ & $\begin{array}{l}\text { 'Systemic antimicrobial therapy using a combination of AMX } \\
\text { and MET as an adjunct to SRP can enhance the clinical benefits } \\
\text { of non-surgical periodontal therapy in adults who are other- } \\
\text { wise healthy' }\end{array}$ \\
\hline
\end{tabular}

antimicrobials seemed to increase the risk of side effects compared to SRP alone. Finally, we did not find much data reporting on bacterial resistance, which reduced our confidence that the use of antibiotics may be acceptable. Nevertheless, it is important to emphasise that most trials included in the SRs had a short follow-up which hinders more robust conclusions on the effects of antimicrobials on tooth survival and bacterial resistance.
It is important to clarify to the reader that the current overview is based on the assessment of SRs which evaluated primary data (that is, clinical trials on interventions). So, all data presented (for example, the data reported in tables) are derived from information already reported in the SRs included. No attention was paid to data extraction from primary studies. Moreover, some overlapping of primary studies included in the SRs is to be expected because of the similarity of review objectives (that is, evaluation of the use of antimicrobials in the treatment of periodontitis). For example, four RCTs included in one $\mathrm{SR}^{25}$ were found in another $\mathrm{SR}^{24}$, which included a total of 19 trials.

The efficacy results based on surrogate endpoints showed statistical differences between the groups. These differences were reduced when the average depth of all 
Table 4 Clinical effect of systemic antibiotics as an adjuvant treatment for periodontitis (PD $>5 \mathrm{~mm}$ at baseline)

\begin{tabular}{|c|c|c|c|}
\hline \multirow[t]{2}{*}{ Studies } & Results on effectiveness (in mm) & & $\begin{array}{l}\text { Number of studies included } \\
\text { in the meta-analysis }\end{array}$ \\
\hline & Fixed-effect model & $\begin{array}{l}\text { Random- } \\
\text { effect model }\end{array}$ & \\
\hline $\begin{array}{l}\text { Hayes et al. } \\
1992^{*, 19}\end{array}$ & $\begin{array}{l}\text { (Initial PD } \geq 5 \mathrm{~mm} \text { ) } \\
\text { PD (NT: } 0.65 ; \text { SRP: } 2.02 \text {; only tetra: } 1.98 \text {; } \\
\text { tetracycline +SRP: } 2.45 \text { ) }\end{array}$ & - & 2 \\
\hline $\begin{array}{l}\text { Elter et al. } \\
1997^{20}\end{array}$ & $\begin{array}{l}\mathrm{PD}(0.7, \mathrm{Cl}: 0.12 \text { to } 1.27) \text { in } \mathrm{PD} \geq 7 \mathrm{~mm} \text { at } \\
\text { baseline); } \mathrm{CAL}(0.193, \mathrm{Cl}:-0.23 \text { to } 0.62) \\
\text { in } \mathrm{CAL} \geq 7 \mathrm{~mm} \text { at baseline }\end{array}$ & - & 3 for $\mathrm{PD} ; 3$ for $\mathrm{CAL}$ \\
\hline $\begin{array}{l}\text { Herrera et al. } \\
2002^{21}\end{array}$ & $\begin{array}{l}\text { (in PD >6 mm at baseline) } \\
\text { PD (spyramicin:0.407, Cl: } 0.081 \text { to } 0.733 \text { ); } \\
\text { CAL (spyramicin: } 0.262, \mathrm{Cl}:-0.044 \text { to } \\
\text { 0.569), (AMX/MET: } 0.450, \mathrm{Cl}: 0.192 \text { to } \\
\text { 0.709), (MET: } 0.551, \mathrm{Cl}:-0.017 \text { to } 1.119 \text { ) }\end{array}$ & - & $\begin{array}{l}2 \text { for PD; } \\
2 \text { for CAL }\end{array}$ \\
\hline $\begin{array}{l}\text { Zandbergen } \\
\text { et al. } 2013^{*, 24}\end{array}$ & $\begin{array}{l}\text { (in PD } \geq 6 \mathrm{~mm} \text { at baseline) } \\
\text { PD (-2.59, Cl: }-2.65 \text { to }-2.53) ; \mathrm{CAL}(1.66 \text {, } \\
\mathrm{Cl}: 1.54 \text { to } 1.78) \\
\text { (in PD } \geq 7 \mathrm{~mm} \text { at baseline) } \\
\text { PD }(-3.72, \mathrm{Cl}:-3.83 \text { to }-3.61) ; \mathrm{CAL}(2.66 \text {, } \\
\mathrm{Cl}: 2.51 \text { to } 2.81)\end{array}$ & - & $\begin{array}{l}5 \text { for PD } \\
4 \text { for CAL } \\
8 \text { for PD } \\
8 \text { for CAL }\end{array}$ \\
\hline
\end{tabular}

Table 5 Reported side-effects in systematic reviews with meta-analyses

\begin{tabular}{|c|c|c|}
\hline \multirow[t]{2}{*}{ Studies } & \multicolumn{2}{|l|}{ Results on side-effects } \\
\hline & Test group & Control group \\
\hline $\begin{array}{l}\text { Hayes et al. } \\
1992^{19}\end{array}$ & NR & NR \\
\hline $\begin{array}{l}\text { Elter et al. } \\
1997^{20}\end{array}$ & NR & NR \\
\hline $\begin{array}{l}\text { Herrera et al. } \\
2002^{21}\end{array}$ & $\begin{array}{l}\text { Gastrointestinal problems } \\
\text { Temporary bacterial resistance }\end{array}$ & Gastrointestinal problems \\
\hline $\begin{array}{l}\text { Haffajee et al. } \\
2003^{22}\end{array}$ & Diarrhea & - \\
\hline $\begin{array}{l}\text { Bono et al. } \\
2010^{23}\end{array}$ & NR & NR \\
\hline $\begin{array}{l}\text { Sgolastra et al. } \\
2012^{25}\end{array}$ & Types of adverse events not reported & - \\
\hline $\begin{array}{l}\text { Sgolastra et al. } \\
2012 b^{26}\end{array}$ & Diarrhea and vomiting & - \\
\hline $\begin{array}{l}\text { Sgolastra et al. } \\
2013^{27}\end{array}$ & No serious side effects occurred & - \\
\hline $\begin{array}{l}\text { Zandbergen et } \\
\text { al. } 2013^{24}\end{array}$ & $\begin{array}{l}\text { Nausea, vomiting, and gastrointestinal discomfort,: } \\
\text { headaches and a metallic taste, general unwellness, burn- } \\
\text { ing sensation of the mouth or tongue, musculoskeletal } \\
\text { disorder, respiratory disorder, tooth loss, taste alterations, } \\
\text { dry mouth, erythema, oral ulceration, dizziness, staining of } \\
\text { tongue or teeth, irritability, a rash on the face or neck, and } \\
\text { nausea after the use of alcohol. }\end{array}$ & - \\
\hline
\end{tabular}

pockets was used as a reference. The greatest difference in mean PD favouring the antimicrobials group was $1.41 \mathrm{~mm} .{ }^{24}$ The greatest CAL gain, $0.94 \mathrm{~mm}$ in the group treated with systemic antibiotics, was reported in the same SR. ${ }^{24}$ The analyses of improvements of deeper pockets generated more pronounced differences, although they were reported in only one of the four SRs, ${ }^{24}$ which reported data based on PD sub-groups (Table 4). Herrera et al. $2002^{21}$ assessed the effect of amoxicillin and metronidazole, among several antimicrobials and their combinations. This $\mathrm{SR}^{21}$ showed less pronounced differences in CAL measurements in patients treated with amoxicillin and metronidazole than Zandbergen et al. 2013, ${ }^{24}$ which reviewed the same combination of antimicrobials. Herrera et al. (pockets $>6 \mathrm{~mm}$ ) and Zandbergen et al. (pockets $>6 \mathrm{~mm}$ ) reported that pockets $>6 \mathrm{~mm}$ at baseline improved in the group using antimicrobials by $0.450 \mathrm{~mm}$ and $1.66 \mathrm{~mm}$ on average, respectively. Zandbergen et al. also reported a greater improvement in CAL measurements in the antimicrobials group with $>7 \mathrm{~mm}$ pockets at baseline. The differences in the results reported in these studies may be explained by the time of publication. Many newer studies were included in the 2013 SR. In addition, the inclusion/exclusion criteria differed between them.

A limitation of the present overview of the effectiveness of antimicrobials in the treatment of periodontitis is that authors of SRs evaluated the data in different ways. Some authors assessed CAL or PD taking into account the average CAL or PD changes from 'all teeth' involved. Others used a specific threshold of severity (for example, PD at baseline $>5 \mathrm{~mm}$ ). Furthermore, some meta-analyses seem to be performed with the inclusion of patients with different disease classifications (aggressive vs. chronic periodontitis). This approach hinders a better understanding of whether there are in fact different outcomes after the use of antimicrobials in aggressive or chronic forms of periodontitis. The distinction between these two entities is, nevertheless, not easy to make, ${ }^{28}$ and some misinterpretation by authors of primary studies in classifying the disease might be expected.

Although there is a lack of information on potential relevant side effects of antimicrobials such as bacterial resistance, the importance of the topic deserves a more in-depth discussion. The risk of bacterial resistance is an ongoing issue of concern in the literature. ${ }^{29,30}$ In the USA in 2009, more than three million kilograms of antimicrobials were administered to patients and, in 2010, 13 million kilograms were administered to animals. ${ }^{29}$ The uncontrolled use of antimicrobials may contribute to increases in bacterial resistance. Although bacterial resistance was only noted in one of the MAs we studied, the data for reducing the use of antibiotics in all patients is compelling. A recently published SR with MA investigated subsequent antimicrobial resistance in individuals prescribed antimicrobials in primary care. ${ }^{12}$ They found that individuals prescribed an antimicrobial for a urinary infection developed bacterial resistance to that antimicrobial (pooled odds ratio [OR] for resistance was 2.5 [95\% confidence interval 2.1 to 2.9] within 2 months of antimicrobial treatment). Similarly, individuals prescribed an antimicrobial in primary care for a respiratory infection developed bacterial resistance to that antibiotic (pooled 
OR for resistance was 2.4 [95\% confidence interval 1.4 to 3.9] within two months of antibiotic treatment). Furthermore, the study found that higher quantities of prescribed antimicrobials, longer duration and multiple courses were associated with higher rates of resistance. While the normal prescription of antimicrobials for treating periodontitis is usually a few days, patients may receive more than one course to treat (or re-treat) periodontitis. Moreover, periodontitis patients may receive similar combinations of antimicrobials to treat other health conditions, perhaps with multiple courses, thus increasing the risk of bacterial resistance.

Theoretically therapeutic improvements in CAL could lead to reduced tooth mortality, however, evidence suggests that clinical attachment loss might be moderately informative on overall tooth mortality. ${ }^{31}$ Moreover, increased PD might represent a risk factor for further periodontitis progression ${ }^{32}$ and tooth loss. ${ }^{33}$ The question then is whether the 'extra CAL gain' or 'PD reduction' provided by the use of SRP plus antimicrobials in comparison to SRP alone outweighs the potential side-effects and the potential threat of bacterial resistance to the patient's overall health and welfare. There are, however, methodological limitations to answering this question such as the need to continue the study over many years because the rates of tooth loss are generally low. This would also necessitate large numbers of patients (with greater costs) to allow an adequate sample size after potential patient drop-outs to reach more robust conclusions.

The methodological qualities of SRs with meta-analyses were heterogeneous. Generally, SRs published more recently (from 2012 to present) had better AMSTAR scores than earlier SRs (Table S1 in the Appendix). This difference may be explained by the increasing awareness of the methods for producing methodologically robust studies. Another important consideration is that the interventions in primary studies varied. For example, different dosages and lengths of treatments were used, different instruments were used, and the experience of providers varied. Overall, the OQAQ checklist provided more positive results than AMSTAR. This might be explained by the grade of subjectivity on the checklist questions, which apparently allows a more positive judgement than AMSTAR. There was also heterogeneity among SRs regarding the type and combinations of antimicrobials (Table 2). Thus, in order to allow a reasonable comparison of the clinical effect of antimicrobials, only information that could be directly compared was retrieved (for example, in the case of Herrera et al. $2002^{21}$ and Zandbergen et al. 201324).

\section{Future research directions}

Long-term studies of sufficient sample size, that also record outcomes such as tooth survival are required, ${ }^{34}$ funding permitting. Currently, systematic reviewers must use lower quality studies to find data on tooth survival. Furthermore, the dental community should reach a consensus on the definition of the most appropriate endpoints, other than tooth survival, to evaluate the benefits of antimicrobials in periodontitis treatment. Additional research efforts could, for example, focus on high quality studies on strategies to moderate host inflammation in response to infections. ${ }^{29}$ The efficacy of host modulatory therapies for the treatment of periodontitis, as well as potential sideeffects, have not been determined..$^{35}$ Other treatments such as immune-based therapies or biologic agents that do not kill bacteria, but change the disease processes ${ }^{29}$ may be alternative treatments that do not contribute to bacterial resistance.

\section{CONCLUSION}

This overview of SRs revealed that the reporting of data on true endpoints such as tooth survival and bacterial resistance is lacking. So, due to the lack of confidence on the benefit of antimicrobials in improving tooth survival following periodontal treatment, clinicians are advised to discuss these limitations with their patients in order to carefully weigh benefits and potential harm when this therapy is proposed.

1. Hirschfeld L, Wasserman B. A long-term survey of tooth loss in 600 treated periodontal patients. J Periodontol 1978; 49: 225-237.

2. Lindhe J, Westfelt E, Nyman S, Socransky S S Haffajee A D. Long-term effect of surgical/nonsurgical treatment of periodontal disease. J Clin Periodontol 1984; 11: 448-458.

3. Wood W R, Greco G W, McFall WT Jr. Tooth loss in patients with moderate periodontitis after treatment and long-term maintenance care. J Periodontol 1989; 60: 516-520.

4. Tonetti M S, Steffen P, Muller-Campanile V, Suvan J, Lang N P. Initial extractions and tooth loss during supportive care in a periodontal population seeking comprehensive care. J Clin Periodontol 2000; 27: 824-831.

5. König J, Plagmann H C, Rühling A, Kocher T. Tooth loss and pocket probing depths in compliant periodontally treated patients: a retrospective analysis. J Clin Periodontol 2002; 29: 1092-1100.

6. Faggion C M Jr, Petersilka G, Lange D E, Gerss J, Flemmig T F. Prognostic model for tooth survival in patients treated for periodontitis. J Clin Periodontol 2007; 34: 226-231.

7. Ehmke B, Moter A, Beikler T, Milian E, Flemmig T F. Adjunctive antimicrobial therapy of periodontitis: long-term effects on disease progression and oral colonization. J Periodonto/ 2005; 76: 749-759.

8. Matarazzo F, Figueiredo L C, Cruz S E, Faveri M, Feres $M$. Clinical and microbiological benefits of systemic metronidazole and amoxicillin in the treatment of smokers with chronic periodontitis: a randomized placebo-controlled study. J Clin Periodontol 2008; 35: 885-896.

9. Cionca N, Giannopoulou C, Ugolotti G, Mombelli A. Amoxicillin and metronidazole as an adjunct to full-mouth scaling and root planing of chronic periodontitis. J Periodontol 2009; 80: 364-371.

10. Aimetti M, Romano F, Guzzi N, Carnevale G. Fullmouth disinfection and systemic antimicrobial therapy in generalized aggressive periodontitis: a randomized, placebo-controlled trial. J Clin Periodontol 2012: 39: 284-294.

11. Dancer S J. How antibiotics can make us sick: the less obvious adverse effects of antimicrobial chemotherapy. Lancet Infect Dis 2004; 4: 611-619.

12. Costelloe $C$, Metcalfe $C$, Lovering A, Mant D, Hay A D. Effect of antibiotic prescribing in primary care on antimicrobial resistance in individual patients: systematic review and meta-analysis. BMJ 2010; 340: c2096.

13. Smith V, Devane D, Begley C M, Clarke M. Methodology in conducting a systematic review of systematic reviews of healthcare interventions. BMC Med Res Methodol 2011; 11: 15.

14. Hujoel P P, DeRouen T A. A survey of endpoint characteristics in periodontal clinical trials published 1988-1992, and implications for future studies. J Clin Periodontol 1995; 22: 397-407.

15. World Health Organisation. WHO Draft Guidelines for Adverse Event Reporting and Learning Systems. 2005. Online information available at http:// www.who.int/patientsafety/events/05/Reporting_ Guidelines.pdf?ua=1 (accessed August 2014).

16. Shea B J, Grimshaw J M, Wells G A et al. Development of AMSTAR: a measurement tool to assess the methodological quality of systematic reviews. BMC Med Res Methodol 2007; 7: 10.

17. Shea B J, Hamel C, Wells G A et al. 2009. AMSTAR is a reliable and valid measurement tool to assess the methodological quality of systematic reviews. J Clin Epidemiol 2009; 62: 1013-1020.

18. Oxman A D, Guyatt G H. Validation of an index of the quality of review articles. J Clin Epidemiol 1991; 44: 1271-1278.

19. Hayes C, Antczak-Bouckoms A, Burdick E. Quality assessment and meta-analysis of systemic tetracycline use in chronic adult periodontitis. J Clin Periodontol 1992; 19: 164-168.

20. Elter J R, Lawrence H P, Offenbacher S, Beck J D. Meta-analysis of the effect of systemic metronidazole as an adjunct to scaling and root planing for adult periodontitis. J Periodontal Res 1997; 32: 487-496.

21. Herrera D, Sanz M, Jepsen S, Needleman I, Roldán S. A systematic review on the effect of systemic antimicrobials as an adjunct to scaling and root planing in periodontitis patients. J Clin Periodonto/ 2002; 29 Suppl 3: 136-159.

22. Haffajee A D, Socransky S S, Gunsolley J C. Systemic anti-infective periodontal therapy. A systematic review. Ann Periodontol 2003; 8: 115-181.

23. Bono A, Brunotto M. Amoxicillin/metronidazole or scaling and root planing in the treatment of chronic periodontitis. Acta Odontol Latinoam 2010; 23 : 196-203.

24. Zandbergen D, Slot D E, Cobb C M, Van der Weijden $F A$. The clinical effect of scaling and root planing and the concomitant administration of systemic amoxicillin and metronidazole: a systematic review. J Periodontol 2013; 84: 332-351.

25. Sgolastra F, Gatto R, Petrucci A, Monaco A. Effectiveness of systemic amoxicillin/metronidazole as adjunctive therapy to scaling and root planing in the treatment of chronic periodontitis: a systematic review and meta-analysis. J Periodonto/ 2012; 83: 1257-1269.

26. Sgolastra F, Petrucci $A$, Gatto R, Monaco A Effectiveness of systemic amoxicillin/metronidazole as an adjunctive therapy to full-mouth scaling and root planing in the treatment of aggressive periodontitis: a systematic review and meta-analysis. J Periodontol 2012; 83: 731-743.

27. Sgolastra F, Severino M, Petrucci $A$, Gatto R, Monaco A. Effectiveness of metronidazole as an adjunct to scaling and root planing in the treatment of chronic periodontitis: a systematic review and meta-analysis. J Periodontal Res 2014; 49: 10-19.

28. Armitage G C, Cullinan M P. Comparison of the clinical features of chronic and aggressive periodontitis. Periodontol 2000 2010; 53: 12-27.

29. Spellberg B, Bartlett J G, Gilbert D N. The future of antibiotics and resistance. N Eng/ J Med 2013; 368: 
299-302.

30. Gulland A. Science ministers discuss the growing threat of antimicrobial resistance. BMJ 2013; 346: f3921.

31. Hujoel P P, Löe H, Anerud A, Boysen H, Leroux B G The informativeness of attachment loss on tooth mortality. J Periodontol 1999; 70: 44-48.

32. Renvert $S$, Persson G R. A systematic review on the use of residual probing depth, bleeding on probing and furcation status following initial periodontal therapy to predict further attachment and tooth loss. J Clin Periodonto/ 2002; 29 (Suppl 3): 82-89. 33. Matuliene G, Pjetursson B E, Salvi G E et al. Influence of residual pockets on progression of periodontitis and tooth loss: results after 11 years of maintenance. J Clin Periodontol 2008; 35: 685-695.
34. Cunha-Cruz J, Hujoel P P, Maupome G, Saver B. Systemic antibiotics and tooth loss in periodonta disease. J Dent Res 2008; 87: 871-876.

35. Sgolastra F, Petrucci A, Gatto R, Giannoni M, Monaco A. Long-term efficacy of subantimicrobialdose doxycycline as an adjunctive treatment to scaling and root planing: a systematic review and meta-analysis. J Periodontol 2011; 82: 1570-1581.

\section{APPENDIX}

Table S1 AMSTAR results. The numbers on the top of the columns refer to the AMSTAR items (reported in the checklist). 1: criterion met; 0 : criterion not met

\begin{tabular}{|l|l|l|l|l|l|l|l|l|l|l|l|}
\hline Study & 1 & 2 & 3 & 4 & 5 & 6 & 7 & 8 & 9 & 10 & 11 \\
\hline Hayes et al. $1992^{19}$ & 0 & 0 & 0 & 0 & 0 & 0 & 1 & 1 & 0 & 0 & 0 \\
\hline Elter et al. $1997^{20}$ & 0 & 0 & 0 & 0 & 0 & 1 & 0 & 0 & 0 & 0 & 0 \\
\hline Herrera et al. $2002^{21}$ & 1 & 1 & 1 & 0 & 1 & 1 & 1 & 1 & 1 & 0 & 0 \\
\hline Haffajee et al. $2003^{22}$ & 1 & 0 & 0 & 0 & 0 & 1 & 1 & 0 & 1 & 0 & 0 \\
\hline Bono et al. $2010^{23}$ & 0 & 0 & 1 & 0 & 0 & 1 & 1 & 1 & 1 & 0 & 0 \\
\hline Sgolastra et al. $2012^{25}$ & 1 & 1 & 1 & 0 & 1 & 1 & 1 & 1 & 1 & 1 & 0 \\
\hline Sgolastra et al. $2012^{26}$ & 1 & 1 & 1 & 0 & 1 & 1 & 1 & 1 & 1 & 1 & 0 \\
\hline Sgolastra et al. $2013^{27}$ & 0 & 1 & 1 & 0 & 1 & 1 & 1 & 1 & 1 & 1 & 0 \\
\hline Hayes et al. $1992^{19}$ & 1 & 1 & 1 & 0 & 1 & 1 & 1 & 1 & 1 & 0 & 0 \\
\hline
\end{tabular}

Table S2 OQAQ results. The numbers on the top of the columns refer to the OQAQ items (reported in the checklist). 1: criterion met; 0 : criterion not met

\begin{tabular}{|l|l|l|l|l|l|l|l|l|l|}
\hline Study & 1 & 2 & 3 & 4 & 5 & 6 & 7 & 8 & 9 \\
\hline Hayes et al. $1992^{19}$ & 1 & 0 & 1 & 0 & 1 & 1 & 0 & 0 & 1 \\
\hline Elter et al. $1997^{20}$ & 1 & 1 & 1 & 0 & 1 & 1 & 1 & 1 & 1 \\
\hline Herrera et al. $2002^{21}$ & 1 & 1 & 1 & $0^{*}$ & 1 & 1 & 1 & 1 & 1 \\
\hline Haffajee et al. $2003^{22}$ & 1 & 1 & 1 & 1 & 1 & 1 & 1 & 1 & 1 \\
\hline Bono et al. $2010^{23}$ & 1 & 1 & 1 & 0 & 1 & 1 & 0 & 0 & 1 \\
\hline Sgolastra et al. $2012^{25}$ & 1 & 1 & 1 & $0^{*}$ & 1 & 1 & 1 & 1 & 1 \\
\hline Sgolastra et al. $2012^{26}$ & 1 & 1 & 1 & $0^{*}$ & 1 & 1 & 1 & 1 & 1 \\
\hline Sgolastra et al. $2013^{27}$ & 1 & 1 & 1 & 1 & 1 & 1 & 1 & 1 & 1 \\
\hline Hayes et al. $1992^{19}$ & 1 & 1 & 1 & $1^{+}$ & 1 & 1 & 1 & 0 \\
\hline
\end{tabular}

*authors did not report 'consensus'; 'third reviewer used to resolve disagreements;

\section{Table S3 AMSTAR checklist}

\section{Was an 'a priori' design provided?}

The research question and inclusion criteria should be established before the conduct of the review.

Note: Need to refer to a protocol, ethics approval, or pre-determined/a priori published research objectives to score a 'yes'.

\section{Was there duplicate study selection and data extraction?}

There should be at least two independent data extractors and a consensus procedure for disagreements should be in place.

Note: 2 people do study selection, 2 people do data extraction, consensus process or one person checks the other's work.

\section{Was a comprehensive literature search performed?}

At least two electronic sources should be searched. The report must include years and databases used (for example, Central, EMBASE, and MEDLINE). Key words and/ or MESH terms must be stated and where feasible the search strategy should be provided. All searches should be supplemented by consulting current contents, reviews, textbooks, specialized registers, or experts in the particular field of study, and by reviewing the references in the studies found.

Note: If at least 2 sources + one supplementary strategy used, select 'yes' (Cochrane register/Central counts as 2 sources; a grey literature search counts as supplementary).

4. Was the status of publication (that is, grey literature) used as an inclusion criterion?

The authors should state that they searched for reports regardless of their publication type. The authors should state whether or not they excluded any reports (from the systematic review), based on their publication status, language etc.

Note: If review indicates that there was a search for 'grey literature' or 'unpublished literature', indicate 'yes.' SINGLE database, dissertations, conference proceedings, and trial registries are all considered grey for this purpose. If searching a source that contains both grey and non-grey, must specify that they were searching for grey/unpublished lit. 
5. Was a list of studies (included and excluded) provided?

A list of included and excluded studies should be provided.

Note: Acceptable if the excluded studies are referenced. If there is an electronic link to the list but the link is dead, select 'no.'

6. Were the characteristics of the included studies provided?

In an aggregated form such as a table, data from the original studies should be provided on the participants, interventions and outcomes. The ranges of characteristics in all the studies analyzed for example, age, race, sex, relevant socioeconomic data, disease status, duration, severity, or other diseases should be reported.

Note: Acceptable if not in table format as long as they are described as above.

7. Was the scientific quality of the included studies assessed and documented?

'A priori' methods of assessment should be provided (for example, for effectiveness studies if the author(s) chose to include only randomized, double-blind, placebo controlled studies, or allocation concealment as inclusion criteria); for other types of studies alternative items will be relevant.

Note: Can include use of a quality scoring tool or checklist, for example, Jadad scale, risk of bias, sensitivity analysis, etc., or a description of quality items, with some kind of result for EACH study ('low' or 'high' is fine, as long as it is clear which studies scored 'low' and which scored 'high'; a summary score/range for all studies is not acceptable).

8. Was the scientific quality of the included studies used appropriately in formulating conclusions?

The results of the methodological rigor and scientific quality should be considered in the analysis and the conclusions of the review, and explicitly stated in formulating recommendations.

Note: Might say something such as 'the results should be interpreted with caution due to poor quality of included studies.' Cannot score 'yes' for this question if scored 'no' for question 7.

\section{Were the methods used to combine the findings of studies appropriate?}

For the pooled results, a test should be done to ensure the studies were combinable, to assess their homogeneity (that is, Chi-squared test for homogeneity, I2). If heterogeneity exists a random effects model should be used and/or the clinical appropriateness of combining should be taken into consideration (that is, is it sensible to combine?).

Note: Indicate 'yes' if they mention or describe heterogeneity, that is, if they explain that they cannot pool because of heterogeneity/variability between interventions.

10. Was the likelihood of publication bias assessed?

An assessment of publication bias should include a combination of graphical aids (for example, funnel plot, other available tests) and/or statistical tests (for example, Egger regression test, Hedges-Olken).

Note: If no test values or funnel plot included, score 'no'. Score 'yes' if mentions that publication bias could not be assessed because there were fewer than 10 included studies.

11. Was the conflict of interest included?

Potential sources of support should be clearly acknowledged in both the systematic review and the included studies.

Note: To get a 'yes', must indicate source of funding or support for the systematic review AND for each of the included studies.

Yes/No/Can't answer/Not applicable

Shea et al. BMCMed Res Method 2007; 7: 10. doi:10.1186/1471-2288-7-10

\section{Table S4 OQAO checklist}

The purpose of this index is to evaluate the scientific quality (that is, adherence to scientific principles) of research overviews (review articles) published in the medical literature. It is not intended to measure literary quality, importance, relevance, originality, or other attributes of overviews.

The index is for assessing overviews of primary ('original') research on pragmatic questions regarding causation, diagnosis, prognosis, therapy or prevention. A research overview is a survey of research. The same principles that apply to epidemiologic surveys apply to overviews: a question must be clearly specified, a target population identified and accessed, appropriate information obtained from that population in an unbiased fashion, and conclusions derived, sometimes with the help of difference between overviews and epidemiologic surveys the unit of analysis, not the scientific issues that the questions in this index address.

Since most published overviews do not include a methods section it is difficulty to answer some of the questions in the index. Base you answer, as much as possible, on the information provided in the overview. If the methods that were used are reported incompletely relative to a specific item, score that item as 'partially'. Similarly, if there is no information provided regarding what was done relative to a particular question, score it as 'can't tell', unless there is information in the overview to suggest either that the criterion was or was not met.

Were the search methods used to find evidence (original research) on the primary question (s) stated?

$\square$ yes $\square$ partially $\square$ no

Yes is given to meta-analysis reporting categories of sources, including years (for example, databases-Medline) used, and whether these categories were named (for example, Medline). Partial points are given for the category of sources (for example, electronic, hand, register) are named.

Was the search for evidence reasonably comprehensive?

$\square$ yes $\square$ can't tell $\square$ no

Yes is given if at least three categories, one of which must be electronic with key words stated, and any two others (for example, hand, register) are reported. Key words and/or MESH terms must be stated.

Were the criteria used for deciding which studies to include in the overview reported?

$\square$ yes $\square$ partially $\square$ no

This item was thought to be reasonably explicit. If 2 or more items mentioned, yes, if $<2$ mentioned, partially, if none mentioned, no.

Was bias in the selection of studies avoided?

$\square$ yes $\square$ can't tell $\square$ no

Yes is given if at least two reviewers independently assess for inclusion. A consensus must be reached.

Were the criteria used for assessing the validity of the included studies reported?

$\square$ yes $\square$ partially $\square$ no

It was felt that the issues relating to publication bias should not be included in the assessment of this. Yes is given to those meta-analysis reporting 'a priori' methods of validity assessment (for example, if the author(s) chose to include only randomized, double-blind, placebo controlled trials, or allocation concealment as inclusion criteria).

Was the validity of all studies referred to in the text assessed using appropriate criteria (either in selecting studies for inclusion or in analysing the studies that are cited)?

$\square$ yes $\square$ can't tell $\square$ no

This item relates to validity assessment. Yes is given if there is a description of any criteria (either internal or external) used either for inclusion, or for analysis (for example, sensitivity analysis). 
Were the methods used to combine the findings of the relevant studies (to reach a conclusion) reported?

$\square$ yes $\square$ partially $\square$ no

This item was thought to be reasonably explicit.

Were the findings of the relevant studies combined appropriately relative to the primary question the overview addresses?

$\square$ yes $\square$ can't tell $\square$ no

For question 8, if no attempt was made to combine findings, and no statement is made regarding the inappropriateness of combining findings, check 'no'. If a summary (general) estimate is given anywhere in the abstract, the discussion or the summary section of the paper, and it is not reported how the estimate was derived, mark 'no' even if there is a statement regarding the limitations of combing the findings of the studies reviewed. If in doubt mark 'can't tell'.

Were the conclusions made by the author(s) supported by the data and/or analysis reported in the overview?

$\square$ yes $\square$ partially $\square$ no

For an overview to be scored as 'yes' on question 9, data (not just citations) must be reported that supports the main conclusions regarding the primary questions (s) that the overview addresses. If the overview concerns diagnostic/prognostic tests, 'retest is not required' (this ensures that diagnostic/prognostic papers are not scored more rigorously than clinical papers).

How would you rate the scientific quality of the overview?

\begin{tabular}{ccccccc} 
Extensive Flaws & Major Flaws & Minor Flaws & \multicolumn{2}{c}{ Minimal Flaws } \\
$\square$ & $\square$ & $\square$ & $\square$ & $\square$ & $\square$ & $\square$ \\
1 & 2 & 3 & 4 & 5 & 6 & 7
\end{tabular}

The score for question 10, the overall scientific quality, should be based on your answers to the first nine questions. The following guidelines can be used to assist with deriving a summary score. If the 'can't tell' option is used one or more times on the preceding questions, a review is likely to have minor flaws at best and it is difficult to rule out major flaws (that is, a score of 4 or lower). If the 'no' option is used on question 2, 4, 6 or 8 , the review is likely to have major flaws (that is, a score of 3 or less, depending on the number and degree of the flaws). 